\title{
PENGARUH pH LARUTAN ELEKTROLIT TERHADAP TEBAL LAPISAN ELEKTROPLATING NIKEL PADA BAJA ST 37
}

\author{
Febryan Andinata ${ }^{1}$, Fredina Destyorini ${ }^{2}$, Eni Sugiarti ${ }^{2}$, Munasir ${ }^{1}$, \\ Kemas A. Zaini T. ${ }^{2}$ \\ ${ }^{1}$ Jurusan Fisika FMIPA Universitas Negeri Surabaya \\ ${ }^{2}$ Puslit Fisika LIPI \\ Email : vbry4nck3p@gmail.com
}

\begin{abstract}
Abstrak
Penelitian ini menggunakan metode eksperimen. Obyek eksperimen pada penelitian ini adalah plat baja karbon rendah (Baja ST 37) berbentuk plat persegi dengan dimensi $\mathrm{p} \times 1 \times \mathrm{x}$. Penelitian ini melalui beberapa tahapan yaitu, persiapan eksperimen dan pelaksanaan eksperimen. Persiapan eksperimen meliputi persiapan benda kerja, pembersihan benda kerja, serta pengukuran keasaman. Dalam penelitian ini masing-masing terdapat 7 kombinasi perlakuan $\mathrm{pH}$ pencelupan yaitu $\mathrm{pH} 3.02,3.23,3.40,3.62,3.82,4.02,4.20$. Analisis data dalam penelitian ini menggunakan analisis Visual. Hasil didapat disimpulkan bahwa ada perbedaan massa hasil pelapisan nikel akibat larutan elektrolit dengan variasi $\mathrm{pH}$ pada bahan baja karbon rendah dengan taraf signifikasi sebesar 95\%. Proses pelapisan nikel dengan menggunakan metode electroplating untuk bahan baja karbon rendah sebaiknya dilakukan pada $\mathrm{pH}$ yang memiliki tingkat keasaman $\mathrm{pH} 3.00$ pada proses lapis nikel.
\end{abstract}

Kata Kunci : Baja ST 37, pH, Electroplating 


\section{Pendahuluan}

Sejalan dengan perkembangan industri dan kemajuan ilmu pengetahuan dan teknologi, penggunaan logam tidak bisa dipisahkan dari kehidupan manusia. Dengan demikian logam harus tampil sesuai dengan kondisi yang dibutuhkan, misalnya untuk penggunaan logam untuk berbagai perhiasan, maka logam harus tampil indah dan menarik. Untuk peralatan rumah tangga harus kuat dan awet, dan seterusnya. Atas dasar tersebut, dibutuhkan suatu upaya untuk mempercantik maupun melindungi logam dari bahaya kerusakan atau korosi.

Untuk menanggulangi terjadinya bahaya korosi berarti memperkecil pula kemungkinan terjadinya suatu kerugian. Agar logam tidak mudah rusak yang disebabkan oleh pengaruh lingkungan maupun korosi, maka perlu dicari cara untuk melindunginya. Salah satu cara yang digunakan untuk melakukan perlindungan terhadap korosi adalah dengan memberikan lapisan pelindung dari logam. Pelapisan logam dapat dilakukan dengan beberapa cara yaitu secara pelelehan, semprot, endap, vakum, sherazing, rich coating, dan electroplating.

Untuk melindungi logam dengan proses electroplating dibutuhkan listrik arus searah (DC), elektrolit yang disesuaikan dengan lapisan yang akan diinginkan, logam pelapis (anoda), dan benda kerja yang akan dilapis (katoda). Didunia indutri ada beberapa macam logam pelapis yang sering digunakan dalam proses pelapisan secara elektroplating, yaitu tembaga $(\mathrm{Cu})$, Nikel (Ni), dan krom (Cr).

Nikel merupakan logam yang banyak digunakan dalam industry pelapisan logam. Nikel mempunyai sifat tahan terhadap korosi, memiliki kekuatan dan kekerasan yang cukup, keliatan yang baik, serta memiliki daya hantar listrik yang baik. Nikel berwarna putih keperak-perakan, berkristal halus, sehingga apabila dipoles akan tampak rupa yang indah dan mengkilap.
Oleh karena itu penulis bertujuan pada penelitian ini adalah mengetahui pengaruh $\mathrm{pH}$ terhadap berat hasil pelapisan nikel pada Baja ST 37 dengan metode electroplating.

\section{Tinjauan Pustaka}

\subsection{Baja ST 37}

Baja yang penulisannya diawali dengan ST, maka bilangan yang mengikutinya menunjukkan kekuatan tarik minimum (dalam $\mathrm{kg} / \mathrm{mm}^{2}$ ) yang dimiliki baja tersebut. Jadi, baja tipe ST 37 menunjukkan bahwa baja ini mempunyai kekuatan tarik $\leq 37 \mathrm{~kg} / \mathrm{mm}^{2}$.

Baja ST 37 merupakan baja karbon kelas rendah, karena mempunyai kandungan karbon kurang dari 0,3\% dan lebih dari $99 \%$ besi. Tb. 1 menunjukkan kandungan unsur-unsur pembentuk baja ST-37. Baja karbon kelas rendah ini mudah teroksidasi, memiliki kekuatan yang relatif rendah, keuletan yang baik, dan banyak diaplikasikan untuk tabung, pipa, dan komponen mesin berkekuatan rendah.

Tb. 1 Komposisi Baja Karbon Rendah Tipe ST 37

\begin{tabular}{|c|c|c|c|}
\hline Unsur & $\begin{array}{c}\text { Kandungan } \\
(\%)\end{array}$ & Unsur & $\begin{array}{c}\text { Kandungan } \\
(\%)\end{array}$ \\
\hline $\mathrm{Fe}$ & 99,310 & $\mathrm{~S}$ & 0,015 \\
\hline $\mathrm{Mn}$ & 0,375 & $\mathrm{Co}$ & 0,007 \\
\hline $\mathrm{C}$ & 0,118 & $\mathrm{Nb}$ & 0,006 \\
\hline $\mathrm{Si}$ & 0,055 & $\mathrm{Cu}$ & Maks. 0,004 \\
\hline $\mathrm{W}$ & 0,046 & $\mathrm{Mo}$ & Maks. 0,004 \\
\hline $\mathrm{Ni}$ & 0,026 & $\mathrm{Al}$ & Maks. 0,002 \\
\hline $\mathrm{Cr}$ & 0,021 & $\mathrm{~V}$ & Maks. 0,001 \\
\hline $\mathrm{P}$ & 0,017 & - & - \\
\hline
\end{tabular}

\subsection{Nikel (Ni)}

Nikel merupakan unsur kimia yang terletak pada Periode 4 Golongan VIII-B, dengan nomor atom 28 dan massa atom 58,71. Nikel memiliki massa jenis 8,902 $\mathrm{g} / \mathrm{cm}^{3}$, titik lebur $1455{ }^{\circ} \mathrm{C}$, dan titik didih $2827{ }^{\circ} \mathrm{C}$. Struktur kristal nikel adalah FCC (face centered cubic) dengan parameter 
lattice $a=0,35243 \mathrm{~nm}$ (pada $25{ }^{\circ} \mathrm{C}$ ), jarijari atom $0,1246 \mathrm{~nm}$, dan elektronegativitas 1,8. Sebagai logam, nikel memiliki kekuatan dan kekerasan sedang, keliatan dan keuletan baik, daya hantar listrik baik, dan tahan korosi.

\section{Metode Penelitian}

\subsection{Persiapan Substrat Baja ST 37}

Pada mulanya mengampelas permukaan dan sisi substrat hingga mengkilap dengan gosokan searah dan dalam aliran air agar struktur substrat tidak rusak. Lalu diukur dimensi dan massa awal substrat dilakukan dengan menggunakan jangka sorong dan timbangan digital. Kemudian substrat diikat dengan kawat nikel dan dicuci dengan agitasi ultrasonik dalam larutan aseton. Setelah itu dikeringkan dan substrat siap di Electroplating.

\subsection{Pembuatan Larutan Ni-strike}

Mencampurkan $125 \mathrm{~g} \mathrm{NiCl}_{2}$ (sebagai sumber ion $\mathrm{Ni}$ ) dan $62,5 \mathrm{ml} \mathrm{HCl}$ (untuk menurunkan $\mathrm{pH}$ larutan) pada gelas kimia. Lalu kedua bahan tersebut dilarutkan dengan aquades nanopure hingga volume $500 \mathrm{~cm}^{3}$ dan diaduk dengan magnetic stirrer pada temperatur ruang selama 2 jam dalam ruang asam.

\subsection{Pembuatan Larutan Ni-watts}

Mencampurkan $33 \mathrm{~g} \mathrm{NiSO}_{4}, 4,5 \mathrm{~g}$ $\mathrm{NiCl}_{2}, 4 \mathrm{~g} \mathrm{H}_{3} \mathrm{BO}_{3}$, dan 3,3 $\mathrm{g} \mathrm{CoSO}_{4}$ pada gelas kimia. Ketiga bahan tersebut dilarutkan dalam aquades nanopure hingga volume $500 \mathrm{~cm}^{3}$ dengan cara diaduk menggunakan magnetic stirrer pada temperatur $50{ }^{\circ} \mathrm{C}$ selama 2 jam dalam ruang asam. Kemudian $\mathrm{pH}$ diatur dengan menambah $\mathrm{HCl}$ jika $\mathrm{pH}$ terlalu asam dan menambah $\mathrm{NH}_{4} \mathrm{OH}$ jika $\mathrm{pH}$ terlalu basa dengan variasi $\mathrm{pH} 3.02,3.23,3.4,3.62$, 3.82, 4.02 dan 4.2.

\subsection{Proses Electroplating}

Sampel substrat yang telah siap dimasukkan ke dalam larutan Ni-strike dengan rapat arus $4 \mathrm{~A}$, temperatur ruang dan dalam ruang asam. ( waktu $\pm 30 \mathrm{~s}$ ). Setelah itu substrat dikeringkan dan dimasukkan dalam larutan Ni-watts dengan rapat arus $20 \mathrm{~mA} / \mathrm{cm}^{2}$, Selama proses electroplating, larutan elektrolit tetap diaduk dengan magnetic stirrer. ( Temperatur $\pm 50{ }^{\circ} \mathrm{c}$ dan waktu \pm 2 jam ). Setelah proses electroplating, substrat dikeringkan dan ditimbang dengan Neraca Digital. Sehingga dapat dihitung tebal melalui Persamaan 3.1 (Secara Teknis/Lowenheim) dan Persamaan 3.2 (Secara Teoritis/Faraday) berikut:

$T=\frac{W}{\rho A}$

$\boldsymbol{T}$ adalah tebal lapisan yang terbentuk (cm), $\boldsymbol{W}$ adalah massa lapisan yang terbentuk (massa akhir - massa awal),

$\rho$ adalah massa jenis logam pelapis $\left(\mathrm{g} / \mathrm{cm}^{3}\right)$,

$\boldsymbol{A}$ adalah luas permukaan sampel $\left(\mathrm{cm}^{2}\right)$.

$$
\mathrm{S}=\frac{I \cdot t \cdot B}{Z \cdot F \cdot \rho \cdot A}
$$

I adalah arus yang digunakan dalam NiWatt (Ampere)

$\mathbf{t}$ adalah lama pelapisan (s)

$\mathbf{B}$ adalah berat atom unsur yang dilapiskan

$\mathbf{Z}$ adalah nomor valensi unsur yang dilapiskan.

\section{Hasil dan Pembahasan}

Hasil Nilai Ketebalan Pelapisan Nikel pada Baja ST 37 terhadap pengaruh $\mathrm{pH}$ adalah sebagai Berikut

Tb. 4.1 Data sampel sebelum elektroplating.

\begin{tabular}{|cccccc|}
\hline Sampel & $\boldsymbol{P}(\mathbf{c m})$ & $\boldsymbol{L}(\mathbf{c m})$ & $\boldsymbol{T}(\mathbf{c m})$ & $\boldsymbol{M 0}(\mathbf{g})$ & \multicolumn{1}{c|}{$\boldsymbol{A}$} \\
\hline $\mathbf{1}$ & 1.345 & 1.275 & 0.135 & 1.72784 & 4.138 \\
$\mathbf{2}$ & 1.465 & 1.125 & 0.145 & 1.72721 & 4.047 \\
$\mathbf{3}$ & 1.345 & 1.305 & 0.135 & 1.77846 & 4.225 \\
$\mathbf{4}$ & 1.355 & 1.325 & 0.145 & 1.81201 & 4.366 \\
$\mathbf{5}$ & 1.345 & 1.275 & 0.145 & 1.72445 & 4.19 \\
$\mathbf{6}$ & 1.385 & 1.335 & 0.145 & 1.83828 & 4.488 \\
$\mathbf{7}$ & 1.465 & 1.165 & 0.145 & 1.73851 & 4.176 \\
\hline
\end{tabular}


Tb. 4.2 Data sampel setelah elektroplating.

\begin{tabular}{|c|c|c|c|c|}
\hline \multirow[b]{2}{*}{ Sampel } & \multirow[b]{2}{*}{$M 1(g)$} & \multirow[b]{2}{*}{$\Delta M(g)$} & \multicolumn{2}{|c|}{$T(\mu m)$} \\
\hline & & & Scr. Teknis & $\begin{array}{c}\text { Scr. } \\
\text { Teori }\end{array}$ \\
\hline 1 & 1,96730 & 0,23946 & 64,97578 & \\
\hline 2 & 1,85444 & 0,12723 & 35,28894 & \\
\hline 3 & 1,97397 & 0,19551 & 51,93551 & \\
\hline 4 & 1,99168 & 0,17967 & 46,17615 & 54,12534 \\
\hline 5 & 1,89971 & 0,17526 & 46,96077 & \\
\hline 6 & 1,94614 & 0,10786 & 26,98661 & \\
\hline 7 & 1,81935 & 0,08084 & 21,73051 & \\
\hline
\end{tabular}

Tb. 4.2 menunjukkan adanya perubahan massa yang dimiliki substrat dari sebelum melakukan elektroplating dan sesudahnya. Oleh karena itu, dapat di analisis bahwa terdapat lapisan nikel pada substrat dengan massa tertentu sehingga dapat merubah massa substrat.

Berdasarkan hal tersebut maka didapatkan grafik antara perubahan $\mathrm{pH}$ dengan ketebalan lapisan nikel pada substrat sebagai berikut.

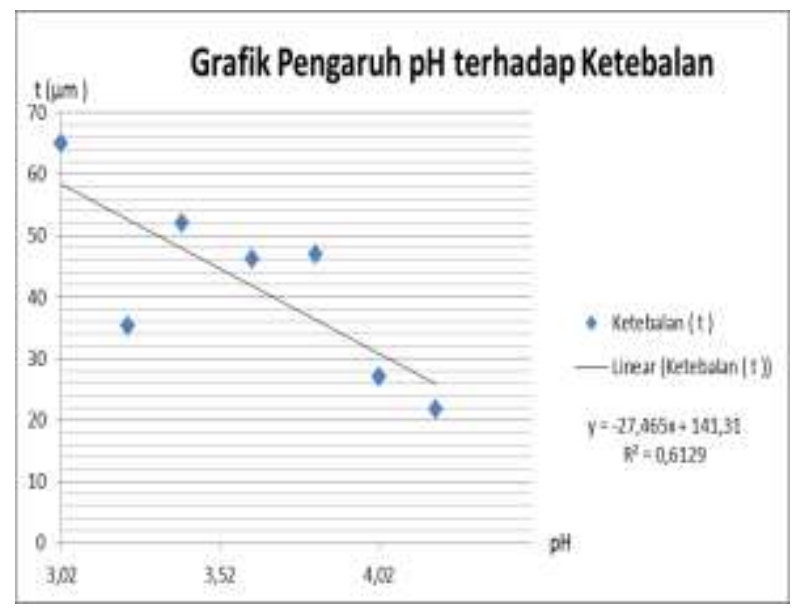

Gb. 4.1 Perubahan $\mathrm{pH}$ terhadap perubahan massa awal dengan setelah elektroplating.

Sehingga berdasarkan data sampel (Tb. 4.1 dan Tb. 4.2 ) dan grafik hasil data sampel ( Gb. 4.1 ). Pada sample 1 (3.02) mengalami kenaikan yang sangat tinggi yaitu $64,97578 \mu \mathrm{m}$ padahal besar $\mathrm{pH} \mathrm{Ni}$ watts yang dimiliki lebih asam sedangkan sampel 2 (3.23) mengalami penurunan yang sangat besar jika dibandingkan dengan sampel awal namun pada sampel 3 (3.40) - sampel 7 (4.20) mengalami penurunan yang signifikan walaupun pada sampel 5 (3.82) mengalami kenaikan terhadap data sampel sebelumnya sedangkan ketika ditinjau dengan menggunakan perumusan hukum faraday tentang tebal lapisan terdeposisi, pengaruh $\mathrm{pH}$ larutan tidak ada.

Hal ini jika di tinjau berdasarkan perilaku ion yang menunjukkan bahwa cepat bereaksi ketika berada di $\mathrm{pH}$ yang asam namun berdasarkan penelitian ini dapat ditunjukkan bahwa terdapat range yang memungkinkan untuk melakukan elektroplating dengan hasil optimal pada pH sekitar 3.4 - 3.8 karena memiliki nilai selisih antar $\mathrm{pH}$ lebih sedikit. Namun jika dibutuhkan untuk mendapatkan lapisan yang lebih tebal dapat menggunakan $\mathrm{pH}$ yang lebih asam dengan resiko lapisan yang dihasilkan tidak merata dan menyatu dengan permukaan substrat sehingga lebih mudah terkelupas jika menggunakan $\mathrm{pH}$ yang lebih basa maka hasil lapisan yang didapatkan akan cenderung sedikit dan tidak merata. Semua hal tersebut tentunya masih harus didukung faktor - faktor lain yang mempengaruhi elektroplating seperti suhu ruang dan lama elektroplating.

\section{Kesimpulan}

Berdasarkan data hasil electroplating. Didapatkan kesimpulan bahwa $\mathrm{pH}$ memiliki pengaruh tinggi terhadap larutan yang akan di deposisikan sesuai dengan rumusan teknis dari Lowenheim walaupun pada rumusan hukum faraday pengaruh $\mathrm{pH}$ tidak dianggap sehingga pada dasarnya, semakin asam larutan elektrolit, maka konsentrasi ion hidrogennya semakin tinggi dan hantaran arus dari anoda ke katoda semakin besar. Sehingga semakin banyak pula ion-ion pelapis yang didistribusikan ke katoda dan lapisan deposisi menjadi semakin tebal. Namun, $\mathrm{pH}$ yang terlalu rendah dapat menyebabkan penurunan konsentrasi ion-ion 
pelapis. Jika hal ini terjadi, maka lapisan yang terdeposisi akan berkurang sehingga lapisan menjadi semakin tipis.

Grafik kurva yang seharusnya didapat adalah linier menurun namun berbeda dengan data hasil percobaan.

Oleh karena itu, ketika pembuatan sampel seharusnya dilakukan dengan ketelitian, sangat hati - hati dan untuk mendapatkan hasil pelapisan nikel yang lebih optimal menggunakan pH 3.00 - 3.80 sesuai perbandingan data pelapisan yang di dapat.

\section{Ucapan Terima Kasih}

Percobaan ini dilakukan dalam rangka bimbingan Praktek Kerja Lapangan (PKL) di Pusat Penelitian Fisika LIPI, periode Agustus 2012, melalui kegiatan SINAS Kementrian RISTEK No. RD-2012-32.

\section{Daftar Pustaka}

[1] http://digilib.unimus.ac.id/files/disk 1/105/ jtptunimus-gdl-wahyudic2a5235-2-bab2.pdf

[2] http://id.wikipedia.org/wiki/Elektroplating.

[3] Arsianto, S. A. 1995. Mengenal Teknik Pelapisan Logam. Bandung : Balai Besar.

[4] Callister, William D.2003."Material Science and Engineering". Sixth Edition.John Willey \& Sons Inc. United States of Amerika.

[5] Fatma, Nurul.2011.Pembuatan Lapisan NiAl Pada Substrat Baja Tipe ST 37 Dengan Kombinasi Metode Deposisi Electroplating dan Pack Cementation.Serpong:LIPI.

[7] Supardi, Rachmat. 1997. Korosi. Bandung : Tarsito.

[8] Tomijiro, K. dan Anton, J. H. 1992. Mengenal Pelapisan Logam (Electroplating). Yogyakarta : Andi Offset. 